\title{
Experimental Studies of Self Healing Behaviour of Under-Aged Al-Mg-Si Alloys and 60Sn-40Pb Alloy Reinforced Aluminium Metal-Metal Composites
}

\author{
Kenneth Kanayo Alaneme ${ }^{1,2^{*}}$, Oluwafemi Isaac Omosule ${ }^{1}$ \\ ${ }^{1}$ Department of Metallurgical and Materials Engineering, Federal University of Technology, Akure, \\ Nigeria \\ ${ }^{2}$ Department of Mining and Metallurgical Engineering, Faculty of Engineering Campus, University of Namibia, \\ Ongwediva, Namibia \\ Email: ${ }^{*}$ kalanemek@yahoo.co.uk
}

Received 31 October 2014; revised 2 December 2014; accepted 15 December 2014

Copyright $@ 2015$ by authors and Scientific Research Publishing Inc.

This work is licensed under the Creative Commons Attribution International License (CC BY). http://creativecommons.org/licenses/by/4.0/

(c) (i)

\section{Abstract}

Experimental studies to demonstrate self healing potentials of Al-Mg-Si alloy were undertaken in this research work. Self healing exploring secondary precipitation in the Al-Mg-Si alloy and use of low melting metallic alloy reinforcement $(60 \mathrm{Sn}-40 \mathrm{~Pb}$ alloy) were used as basis for the investigation. For the precipitation study, the Al-Mg-Si alloy was under-aged at temperature of $160^{\circ} \mathrm{C}$ for 10 minutes and then subjected to second step ageing treatment at four different temperatures within the range of $25^{\circ} \mathrm{C}$ and $70^{\circ} \mathrm{C}$. In the $60 \mathrm{Sn}-40 \mathrm{~Pb}$ alloy reinforced $\mathrm{Al}-\mathrm{Mg}$-Si alloy study, the samples were prepared in pre-cracked state and then subjected to healing heat-treatment at $250^{\circ} \mathrm{C}$. For all cases tensile test and healing efficiency was used to analyze the results generated. It was observed that a second step thermal ageing at $50^{\circ} \mathrm{C}$ resulted in peak improvement in tensile strength, yield strength, toughness and percent elongation while ageing above this temperature lead to a drop in the tensile properties in comparison to that of the sample not subjected to a second ageing treatment. Also the use of $60 \mathrm{Sn}-40 \mathrm{~Pb}$ alloy as reinforcement in the Al-Mg-Si alloy resulted in a healing efficiency of $91 \%$ after pre-cracking and heat-treatment. The satisfactory bonding between the $60 \mathrm{Sn}-40 \mathrm{~Pb}$ alloy and the Al-Mg-Si alloy matrix contributed to the high healing efficiency observed.

\section{Keywords}

Aluminium Alloys, Secondary Precipitation, Self Healing Metals, Healing Efficiency, Mechanical

\footnotetext{
${ }^{*}$ Corresponding author.
} 


\section{Introduction}

Self healing materials are bio-inspired materials designed to mimic the behaviour of biological systems which have the capacity of self healing after undergoing some form of damage (such as blood clotting to seal up an open wound or cut) [1]. In materials systems, the aim is to be able to restore a substantial level of the original functionality (properties) of the material by a self repair process after it has undergone some form of damage [2]. The damage could be in form of micro-cracks, void or flaws developed from mechanical, thermal and other forms of environmental or in-service factors [3] [4].

The design of self healing materials has become attractive since materials designed using traditional materials design concept of "damage prevention" do eventually fail in service due to damage development. The damage management philosophy explored in the design of self healing materials comes to terms with the inevitability of damage occurring and consequently materials functionality waning [5]. Phenomena such as wear, residual stress development, micro-crack formation, and corrosion are among characteristics processed which can induce materials damage [6]. The damage management design philosophy pursues sustaining materials functionality and properties at levels not below $70 \%-80 \%$ of its original value through the process of self repair which is triggered once damage occurs in the materials [2]. A wide range of benefits can accrue from the use of this design concept if it can be applied at commercial levels. It has the potential of reducing cost of maintenance if components are made with self healing materials. This will also reflect in reduced production cost and down time of various industrial processes requiring the repair of damaged parts central to its production operations. This would in turn translate to prolonged service life of components and consistent service performance [7]. There is also the attraction of low energy requirement for developing self healing materials and low design cost of fabricating or incorporating self healing agents in traditional materials [8].

Despite the huge promise of self healing concept of materials design, the science of self healing is still not thoroughly understood and grossly underutilized [9]. Presently, the most successful application of the self healing concept has been in the development of self healing polymers and polymer based composites [10] [11]. This is on account of the high rate of diffusion in polymers due to the presence of cross molecular bonds which facilitates diffusion of healing agents to fill up voids or micro-cracks [10]. In ceramics, some success has been recorded in the development of self healing ceramic systems [12] [13]. However, in metallic material systems which still happen to be the most widely utilized material class, there are still some teething problems [7]. In metals, diffusion rates are significantly lower compared to polymers due to the strong bonds between metal atoms which thus makes self healing much difficult to achieve in metallic systems [14].

Currently, there are three main directions which have been taken in the development of self-healing metallic systems [14]. The formation of under aged precipitates in alloys which still retains a substantial amount of solutes in solid solution which can diffuse as secondary precipitates to close defects created by plastic deformation when treated at lower temperatures thus immobilize further defect growth [15]. Materials or alloy matrix reinforcement with microfibers or wires made of a shape-memory alloy (SMA) is another approach currently explored [16]. If the composite undergoes crack formation, heating the material will activate the shape recovery feature of the SMA wires which then shrink applying compressive force at the cracks and close the cracks [17]. The third approach is by incorporating a low-melting temperature alloy that serves as a healing agent in a highmelting temperature alloy which serves as a matrix [14]. When a crack develops in the composites, by heating to the healing temperature the low-melting point alloy embedded in the matrix becomes completely molten, and by capillary pressure and surface tension, flows out and fill in the crack. As the temperature is reduced, the lowmelting point healing alloy solidifies and seals the crack [7].

The study of these self healing approaches in metallic systems is still very limited and is still in need of further investigations to develop a robust science of self healing in metallic systems. In the present study, experimental investigation of self healing in under-aged Al-Mg-Si alloys and Al-Mg-Si alloy reinforced with 60Sn$40 \mathrm{~Pb}$ low melting alloy is reported. 


\section{Materials and Methods}

\subsection{Materials}

The materials used in this research work are: Al-Mg-Si alloy as received in the form of slabs with chemical compositions as presented in Table 1 and commercial grade tin lead based solders (60Sn-40Pb).

\subsection{Self Healing Experimental Studies}

\subsubsection{Secondary Precipitation Approach}

Precipitation induced self healing was studied following an approach similar to that of Hauta Kangas et al. [18]. The Al-Mg-Si alloy used for the study was machined to specifications for tensile testing with gauge length and diameter of $30 \mathrm{~mm}$ and $5 \mathrm{~mm}$ respectively. The samples were subjected to solution heat-treatment at $500^{\circ} \mathrm{C}$ for 1 hour, and then quenched in water. The samples were then thermally aged at $160^{\circ} \mathrm{C}$ for 10 minutes followed by rapid cooling in a water bath. A second ageing treatment was then performed on the test samples at temperatures of $25^{\circ} \mathrm{C}, 40^{\circ} \mathrm{C}, 50^{\circ} \mathrm{C}, 60^{\circ} \mathrm{C}$, and $70^{\circ} \mathrm{C}$ for period of 12 hours before quenching in water. Thereafter, the samples were subjected to tensile loading to fracture. The tensile testing was performed at a strain rate of $10^{-3} / \mathrm{s}$ and with testing procedures in accordance with ASTM 8M-91 standard [19]. The tests were carried out in triplicates to guarantee the reliability of the results obtained.

\subsubsection{Use of Low Melting Point Reinforcement}

For studies on healing by incorporation of low melting alloy, the tensile samples (Figure 1) were incorporated with the $60 \mathrm{Sn}-40 \mathrm{~Pb}$ based solders fitted within the $3 \mathrm{~mm}$ holes bored into them. Three samples of the tensile test specimens had $1 \mathrm{~mm}$ holes drilled in the surface of the sample to pierce the low melting point $60 \mathrm{Sn}-40 \mathrm{~Pb}$ alloy embedded within the $\mathrm{Al}$ matrix. This was done to simulate crack formation (mechanical damage) on the Al based composite. The samples were afterwards subjected to tensile loading to fracture and the tensile properties evaluated. These set of pre-cracked samples subjected to tensile testing were referred to as damaged samples. Another set of pre-cracked $60 \mathrm{Sn}-40 \mathrm{~Pb}$ reinforced $\mathrm{Al}-\mathrm{Mg}$-Si alloy based composite samples were prepared but this time wrapped with Aluminium foil and heated at a temperature of $250^{\circ} \mathrm{C}$ for 10 minutes before air cooling. The samples were then subjected to tensile testing to fracture and its tensile properties evaluated from the stress-

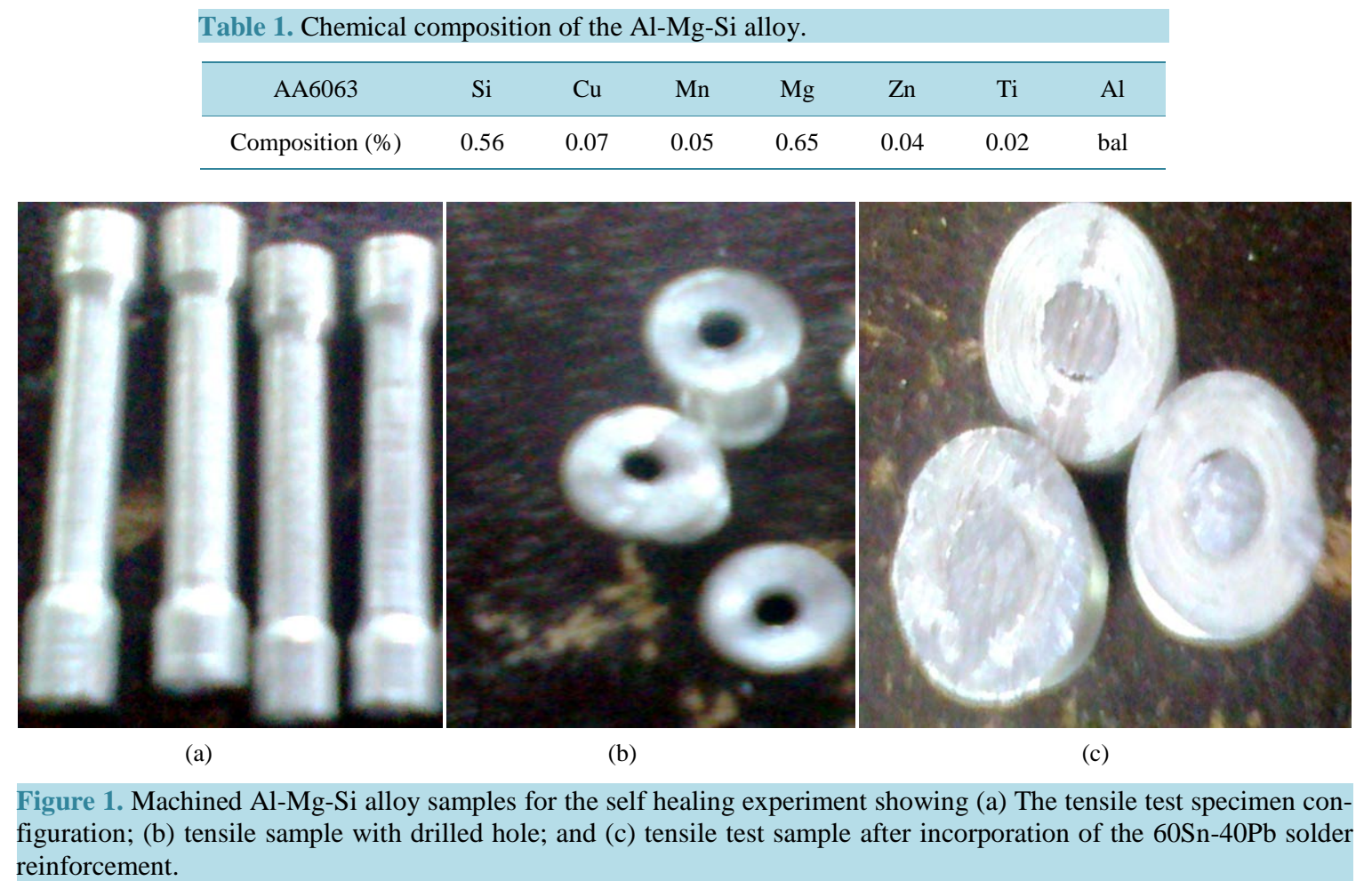


strain plots generated from the testing. The samples were referred to as healed samples. The wrapping with Aluminium foil was done in other to forestall the draining of the $60 \mathrm{Sn}-40 \mathrm{~Pb}$ solder through the drilled hole during the heating process. Finally tensile testing was also conducted on another set of the $60 \mathrm{Sn}-40 \mathrm{~Pb}$ reinforced AlMg-Si alloy samples which were not pre-cracked; which for the purpose of the experiment were referred to as virgin samples. For all test cases the tensile test was carried out at room temperature with the aid of a universal tensile testing machine. The tensile testing was performed at a strain rate of $10^{-3} / \mathrm{s}$ and with testing procedures in accordance with ASTM 8M-91 standard [19]. Repeat tests were performed for all test cases to ensure repeatability and reliability of the data generated.

The self healing efficiency achieved using the $60 \mathrm{Sn}-40 \mathrm{~Pb}$ reinforced $\mathrm{Al}-\mathrm{Mg}-\mathrm{Si}$ alloy based composites was determined using the tensile strength based criterion given by the relation [20]:

$$
\eta_{\text {tensile }}=\frac{\sigma_{\text {healed }}}{\sigma_{\text {virgin }}} \times 100 \%
$$

where $\sigma_{\text {virgin }}$ is the tensile strength of the virgin specimen and $\sigma_{\text {healed }}$ is the tensile strength of the healed specimen.

\subsection{Microstructural Examination}

The microstructures of the $60 \mathrm{Sn}-40 \mathrm{~Pb}$ reinforced $\mathrm{Al}-\mathrm{Mg}$-Si alloy samples were examined in the as-polished and etched conditions using a metallurgical microscope. The etching of the samples was performed by swabbing using Kellers reagent (consisting of $190 \mathrm{ml}$ distilled water, 5 ml HNO $3,3 \mathrm{ml} \mathrm{HCl,} 2 \mathrm{ml} \mathrm{HF}$ ).

\section{Results and Discussion}

\subsection{Tensile Properties of Precipitation Induced Healing Samples}

The tensile properties of the under-aged samples subjected to a second low temperature ageing treatment within the range of $25^{\circ} \mathrm{C}$ and $70^{\circ} \mathrm{C}$ are presented in Figure 2. It is observed from Figure 2(a) that the samples subjected secondary thermal ageing at $40^{\circ} \mathrm{C}$ and $50^{\circ} \mathrm{C}$ had higher tensile strength values compared with the sample at room temperature with peak tensile strength observed for second ageing treatment carried out at $50^{\circ} \mathrm{C}$. It is also observed that ageing above $50^{\circ} \mathrm{C}$ resulted in reduction in the tensile strength values lower than that observed for the primary aged sample. The same trend was also observed for the yield strength (Figure 2(b)) and the toughness (Figure 2(c)). Similar trend with that of the strength parameters and toughness was followed by the \% Elongation (Figure 2(d)) with the exception of the sample treated at $60^{\circ} \mathrm{C}$ which had \% elongation values higher than that of the primary aged sample (sample that remained at room temperature). This clearly shows that strength, ductility and toughness improvement can be induced in under aged Al-Mg-Si alloy by proper selection of the secondary ageing temperature. The improvement in mechanical properties arises from the secondary precipitation of $\mathrm{Mg}_{2} \mathrm{Si}$ from the under aged Al-Mg-Si alloy which still contains solute atoms in excess of the equilibrium concentration. The secondary precipitates are formed at sites referred to as precipitate free zones (PFZ) which are nucleation sites within the matrix where precipitation did not occur during the under ageing primary precipitation treatment. The process of secondary precipitation is reported to be equally accompanied by the process of grain refinement [21]. The results show that the optimum improvement in mechanical properties from the secondary precipitation process is achieved using a secondary ageing temperature of $50^{\circ} \mathrm{C}$. Ageing above this temperature is observed to result in impoverishment of the mechanical properties of the Al-Mg-Si alloy. This is an indicator that processing Al-Mg-Si alloy in the under-aged condition can help in cases where mechanical damage results from service use. A second ageing treatment can be used to recover substantially a part of the mechanical properties so as to prolong the performance and service life of the components or parts.

\subsection{Tensile Property Results for Samples Incorporated with Low Melting 60Sn-40Pb Alloy}

The tensile properties of the Al-Mg-Si alloy samples incorporated with low melting $60 \mathrm{Sn}-40 \mathrm{~Pb}$ alloys are presented in Table 2. It is observed that the pre-cracked sample (damaged sample) had tensile strength value of 43.4 MPa which is $20 \%$ reduction from that of the virgin sample with tensile strength of $54.5 \mathrm{MPa}$. Conducting the self healing treatment at $250^{\circ} \mathrm{C}$ for 10 minutes followed by air cooling, resulted in tensile strength increase from 43.4 MPa (damaged state) to 49.4 MPa (healed state). In comparison with the tensile strength of the virgin 


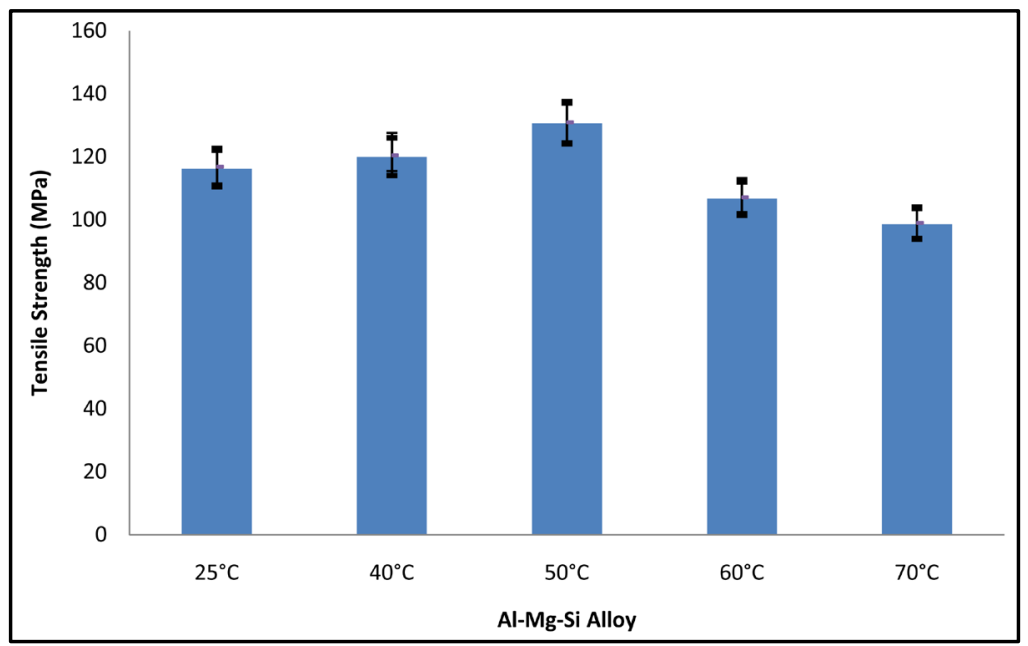

(a)

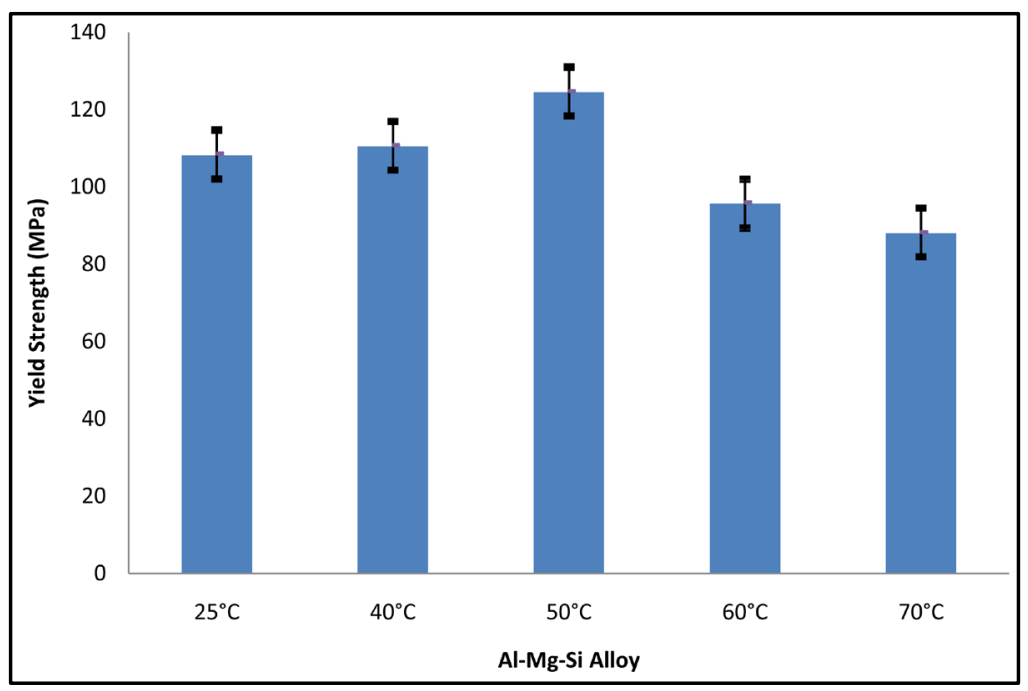

(b)

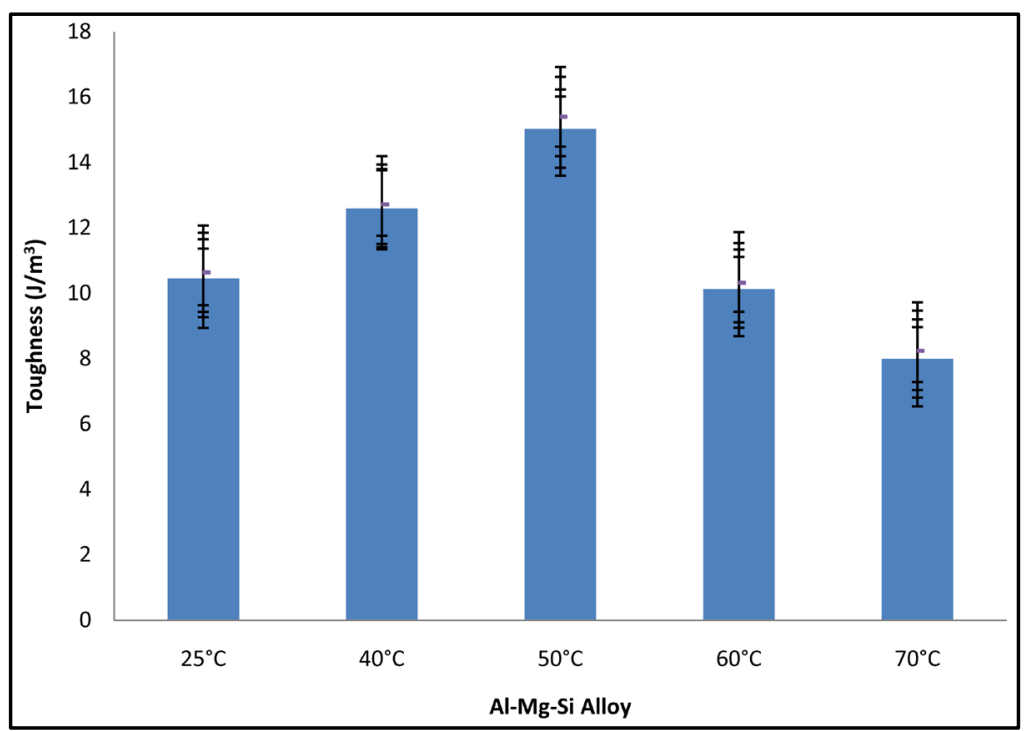

(c) 


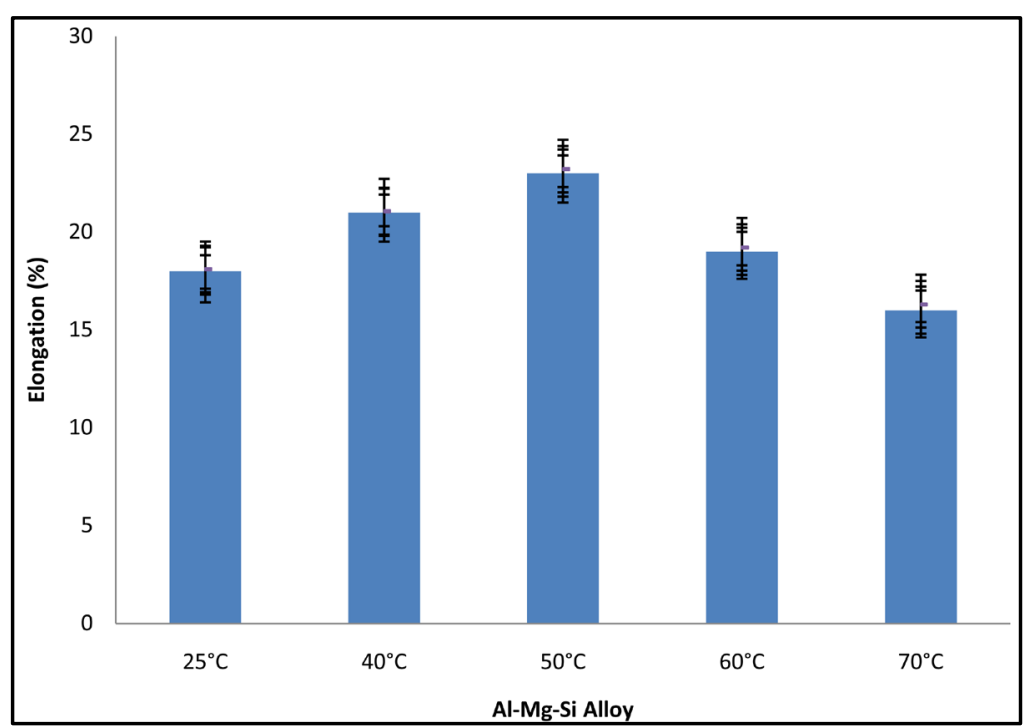

(d)

Figure 2. Tensile properties of the Al-Mg-Si alloy subjected to double ageing treatment showing (a) Tensile Strength; (b) Yield Strength; (c) Toughness; and (d) \% Elongation.

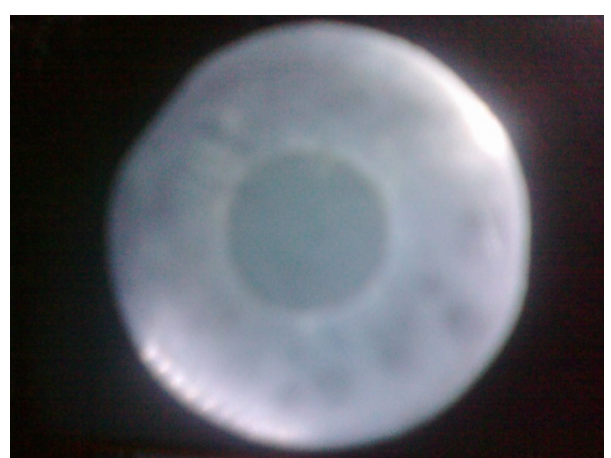

(a)

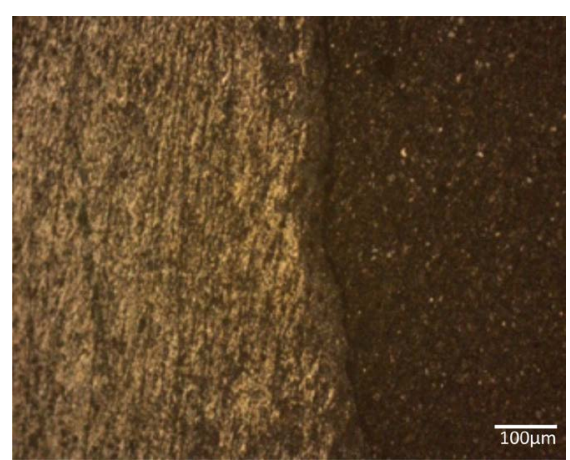

(b)

Figure 3. Optical micrograph of (a) as-polished; and (b) etched sample of the Al-Mg-Si alloy reinforced with $60 \mathrm{Sn}-40 \mathrm{~Pb}$ low melting alloy.

Table 2. Tensile strength and self healing efficiency data for the $60 \mathrm{Sn}-40 \mathrm{~Pb}$ reinforced $\mathrm{Al}-\mathrm{Mg}$-Si alloy based composite.

\begin{tabular}{cccc}
\hline $\begin{array}{c}\text { Tensile Strength (MPa) } \\
\text { (Virgin Sample) }\end{array}$ & $\begin{array}{c}\text { Tensile Strength (MPa) } \\
\text { (Damaged Sample) }\end{array}$ & $\begin{array}{c}\text { Tensile Strength (MPa) } \\
\text { (Healed Sample) }\end{array}$ & $\begin{array}{c}\text { Self Healing Efficiency } \\
\eta_{\text {tensile }}=\frac{\sigma_{\text {healed }}}{\sigma_{\text {virgin }}}\end{array}$ \\
\hline $54.5 \pm 0.15$ & $43.4 \pm 0.30$ & $49.4 \pm 0.50$ & $91 \%$ \\
\hline
\end{tabular}

sample and the use of Equation (1), a healing efficiency of 91\% was achieved. The experimental results are testaments to the promise that self healing (using a low melting alloy as reinforcement) holds to restoring mechanical damage of metallic materials in service. This is achievable particularly if good wetting between the matrix and reinforcement is attained. In the present case, it can be observed from Figure 3 that satisfactory bonding between the $60 \mathrm{Sn}-40 \mathrm{~Pb}$ solder (dark phase) and the Al-Mg-Si alloy matrix (lighter phase) was achieved as the matrix/reinforcement interface show considerable closure.

\section{Conclusions}

Experimental studies to demonstrate self healing potentials of Al-Mg-Si alloy by exploring secondary precipita- 
tion and use of low melting metallic alloy reinforcement (60Sn-40Pb alloy) were investigated. From the results the following conclusions are drawn:

- Second step thermal ageing at $50^{\circ} \mathrm{C}$ resulted in peak improvement in tensile strength, yield strength, toughness and percent elongation while ageing above this temperature lead to a drop in the tensile properties in comparison to that of the sample not subjected to a second ageing treatment.

- The use of $60 \mathrm{Sn}-40 \mathrm{~Pb}$ alloy as reinforcement in the Al-Mg-Si alloy resulted in a healing efficiency of $91 \%$ after pre-cracking and heat-treatment. Satisfactory bonding between the $60 \mathrm{Sn}-40 \mathrm{~Pb}$ alloy and the Al-Mg-Si alloy matrix contributed to the high healing efficiency.

\section{References}

[1] Van der Zwaag, S. (2007) Self-Healing Materials. An Alternative Approach to 20th Centuries of Materials Science. Springer, Berlin, 161-193.

[2] Hayes, S.A., Jones, F.R., Marhiya, K. and Zhang, W. (2005) Self-Healing Composite Materials. Proceedings of the 15th International Conference on Composite Materials, Durban, 27 June-1 July 2005, 24-26.

[3] Pang, J.W.C. and Bond, I.P. (2005) Bleeding Composites-Damage Detection and Self-Repair Using a Biomimetic Approach. Composites Part A: Applied Science and Manufacturing, 36, 183-188. http://dx.doi.org/10.1016/j.compositesa.2004.06.016

[4] Jones, S., Rule, J.D., Moore, J.S., Sottos, N.R. and White, S.R. (2007) Life Extension of Self-Healing Polymers with Rapidly Growing Fatigue Cracks. Journal of the Royal Society Interface, 4, 395-403. http://dx.doi.org/10.1098/rsif.2006.0199

[5] Ghezzo, F., Starr, T.N., Perram, T., Darlington, T.K., Starr A.F. and Smith, D.R. (2010) Development of Self-Healing Composite Materials: Fabrication and Micro-Structural Analyses. 17th International Conference on Composite Materials, ICCM-17, Edinburgh, 27-31 July 2009, 1-7.

[6] Brown, E.N., White, S.R. and Sottos, N.R. (2005) Retardation and Repair of Fatigue Cracks in a Microcapsule Toughened Epoxy Composite—Part I: Manual Infiltration. Composites Science and Technology, 65, 2466-2473. http://dx.doi.org/10.1016/j.compscitech.2005.04.020

[7] Rohatgi, P.K. (2011) Self-Healing Metals and Alloys. United States Patent Application Publication, 1-13.

[8] Lee, J.Y., Buxton, G.A. and Balazs, A.C. (2004) Using Nanoparticles to Create Self-Healing Composites. The Journal of Chemical Physics, 121, 5531-5540. http://dx.doi.org/10.1063/1.1784432

[9] Voyiadjis, G.Z., Shojaei, A. and Li, G. (2011) A Thermodynamic Consistent Damage and Healing Model for Self Healing Materials. International Journal of Plasticity, 27, 1025-1044. http://dx.doi.org/10.1016/j.ijplas.2010.11.002

[10] Trask, R.S., Williams, H. and Bond, I.P. (2007) Self-Healing Polymer Composites: Mimicking Nature to Enhance Performance. Bioinspiration and Biomimetics, 2, 1-9. http://dx.doi.org/10.1088/1748-3182/2/1/P01

[11] Sanada, K., Yasuda, I. and Shindo, Y. (2006) Transverse Tensile Strength of Unidirectional Fibre-Reinforced Polymers and Self-Healing of Interfacial Deboning. Plastic Rubber Composites, 35, 67-72. http://dx.doi.org/10.1179/174328906X79914

[12] Ando, K., Takahashi, K. and Osada, T. (2014) 22-Structural Ceramics with Self-Healing Properties. Handbook of Smart Coatings for Materials Protection. Woodhead Publishing Limited (Elsevier Imprint), UK, 586-605.

[13] Huang, H., Ye, G. and Damidot, D. (2014) Effect of Blast Furnace Slag on Self-Healing of Microcracks in Cementitious Materials. Cement and Concrete Research, 60, 68-82. http://dx.doi.org/10.1016/j.cemconres.2014.03.010

[14] Lumley, R.N., Cairney, J.M. and Ringered, S.P. (2007) Self-Healing in Metals: An Emerging Phenomenon in Metallurgy. Materials Forum, 31, 40-51.

[15] Karpov, E.G., Grankin, M.V., Liu, M. and Ariyan, M. (2012) Characterization of Precipitative Self-Healing Materials by Mechanokinetic Modeling Approach. Journal of the Mechanics and Physics of Solids, 60, 250-260. http://dx.doi.org/10.1016/j.jmps.2011.11.001

[16] Rohatgi, P.K. (2014) Al-Shape Memory Alloy Self-Healing Metal Matrix Composite. Materials Science and Engineering: A, 619, 73-76. http://dx.doi.org/10.1016/j.msea.2014.09.050

[17] Ferguson, J.B., Schultz, B.F. and Rohatgi, P.K. (2014) Zinc Alloy ZA-8/Shape Memory Alloy Self-Healing Metal Matrix Composite. Materials Science and Engineering: A, 620, 85-88. http://dx.doi.org/10.1016/j.msea.2014.10.002

[18] Haukangas, S., Schut, H., Van der Zwaag, S., Rivera diaz del Castillo, P.E.J. and Van Dijk, N.H. (2007) The Role of the Aging Temperature on the Self Healing Kinetics in an Underaged AA2024 Aluminium Alloy. Proceedings of the 1st International Conference on Self Healing Materials, Noordwijk aan Zee, 18-20 April 2007, 1-7.

[19] ASTM E 8M Standard (1991) Test Method for Tension Testing of Metallic Materials (Metric). Annual Book of ASTM 
Standards, Philadelphia.

[20] Sanada, K., Yasuda, I. and Shindo, Y. (2006) Transverse Tensile Strength of Unidirectional Fibre-Reinforced Polymers and Self-Healing of Interfacial Deboning. Plastic Rubber Composites, 35, 67-72. http://dx.doi.org/10.1179/174328906X79914

[21] Nie, J. (2014) 20-Physical Metallurgy of Light Alloys, Physical Metallurgy. 5th Edition, Elsevier, Amsterdam, 20092156. http://dx.doi.org/10.1016/B978-0-444-53770-6.00020-4 
Scientific Research Publishing (SCIRP) is one of the largest Open Access journal publishers. It is currently publishing more than 200 open access, online, peer-reviewed journals covering a wide range of academic disciplines. SCIRP serves the worldwide academic communities and contributes to the progress and application of science with its publication.

Other selected journals from SCIRP are listed as below. Submit your manuscript to us via either submit@scirp.org or Online Submission Portal.
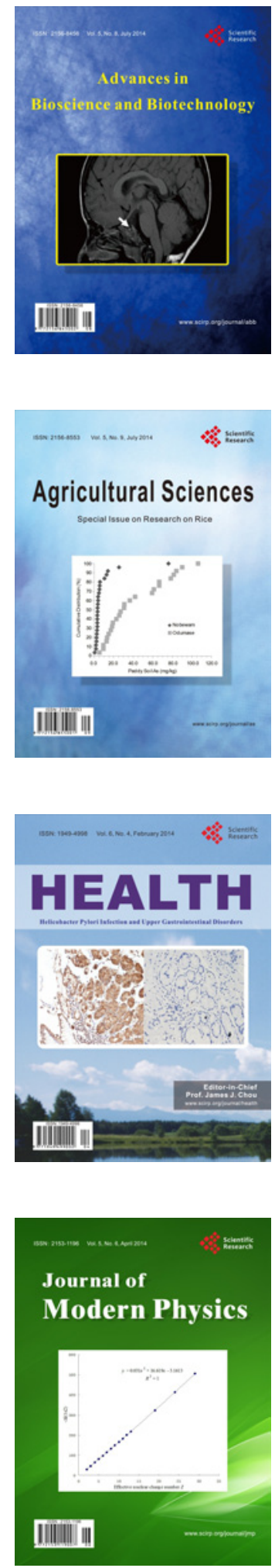
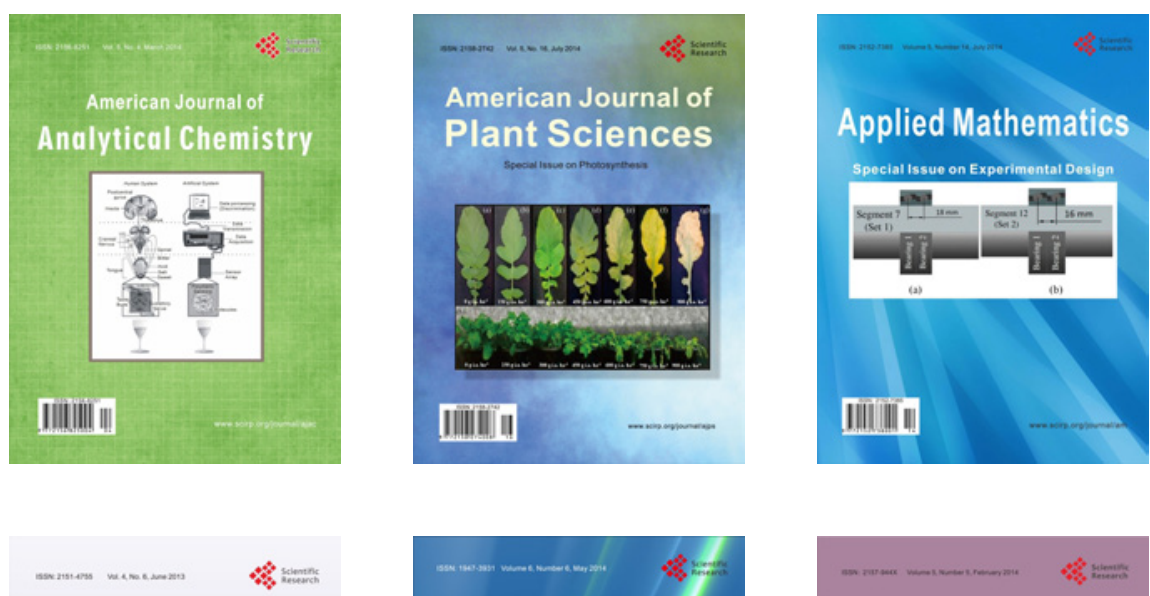

Creative Education
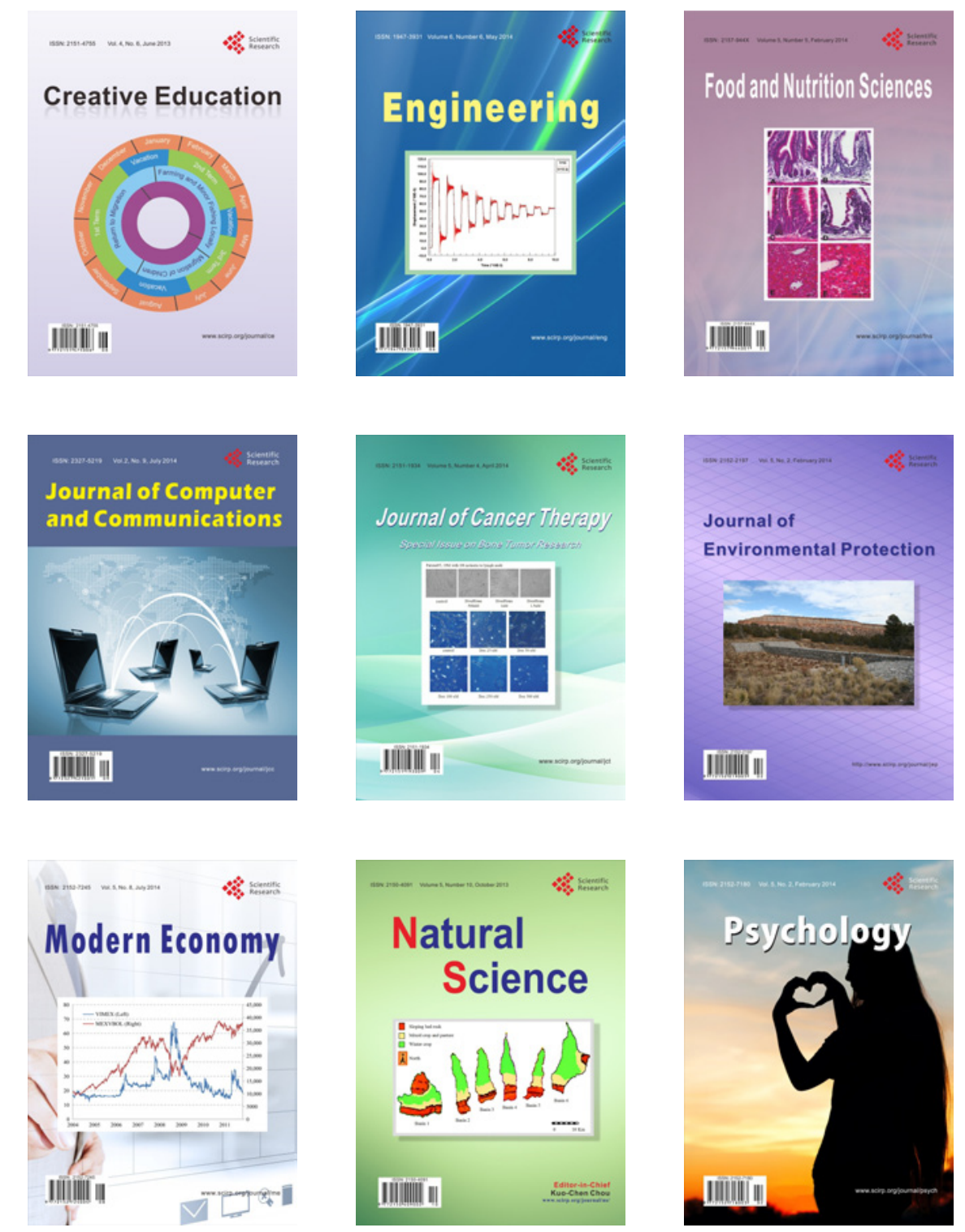